\title{
Formation of a state with high strength and electrical conductivity in the $\mathrm{Cu}-0.5 \% \mathrm{Cr}-0.2 \% \mathrm{Zr}$ alloy
}

\author{
Elena Sarkeeva ${ }^{1,4,{ }^{*}, \text { Marina Abramova }}{ }^{1,4}$, and Wei $\mathrm{Wei}^{2,3,4,{ }^{*}}$ \\ ${ }^{1}$ Ufa State Aviation Technical University, 12 K. Marx, 450000 Ufa, Russia \\ ${ }^{2}$ School of Materials Science and Engineering, Changzhou University, 1 Gehu Road, Changzhou 213164, P.R .China \\ ${ }^{3}$ Jiangsu Key Laboratory of Materials Surface Science and Technology, Changzhou University, Changzhou 213164, P.R. China \\ ${ }^{4}$ Joint Laboratory of Functional Nanostructured Metals, Changzhou University, Changzhou 213164, P.R. China
}

\begin{abstract}
The effect of severe plastic deformation by high pressure torsion (HPT) and subsequent aging on the formation of a high-strength state with sufficient electrical conductivity in the $\mathrm{Cu}-0.5 \% \mathrm{Cr}-0.2 \% \mathrm{Zr}$ (wt.\%) alloy is investigated. It is shown that as a result of HPT and subsequent aging a high-strength state with a tensile strength of $\approx 900 \mathrm{MPa}$ and a conductivity of $70 \%$ IACS can be formed.
\end{abstract}

\section{Introduction}

Low-alloy dispersion-hardened copper alloys of the $\mathrm{Cu}-$ $\mathrm{Cr}-\mathrm{Zr}$ system have a high electrical and thermal conductivity $[1,2]$. The introduction of a small addition of zirconium leads not only to an increase in strength properties, but also to a significant improvement in ductility at elevated temperatures. Alloys of this system are traditionally used in applications where a combination of high mechanical strength, heat resistance and electrical conductivity for manufacturing of contact wires, spot welding electrodes, fusion reactors, etc. is required.

The main factors affecting both the strength and the ductility of these alloys are the grain size, dislocation structure, and concentration of alloying elements in the solid solution, as well as concentration, distribution and size of dispersed particles of the second phases both in the body and at the grain boundaries.

Previous studies have shown that hardening with conventional aging is limited due to the low solubility of $\mathrm{Cr}$ and $\mathrm{Zr}$ in the copper matrix [3]. There are also many studies on the character, composition and distribution of particles formed during the aging of these alloys [4-6]. These studies have shown that particles of the composition $\mathrm{CrCu}_{2}, \mathrm{Cu}_{3} \mathrm{Zr}, \mathrm{Cu}_{5} \mathrm{Zr}$ are precipitated.

The conventional industrial scheme for processing copper alloys of the $\mathrm{Cu}-\mathrm{Cr}-\mathrm{Zr}$ system includes 3 stages: 1 stage - preliminary heat treatment to obtain a supersaturated solid solution (SS), stage 2 - cold deformation to increase strength due to cold work, stage 3 - post-deformation heat treatment, during which the SS decays and dispersed-hardening particles of secondary phases precipitate. As a result, in the alloys of the $\mathrm{Cu}-\mathrm{Cr}-$ $\mathrm{Zr}$ system strength values of the order of 400-500 MPa are attained at an electrical conductivity of $75-80 \%$ of the conductivity of pure copper (IASC). But even higher strength is required by manufactures.
Recent studies have shown that severe plastic deformation (SPD) can significantly increase the strength of materials due to the formation of ultrafine-grained (UFG) structure [7,8]. Previous studies of the strength and electrical conductivity of $\mathrm{Cu}-\mathrm{Cr}-\mathrm{Zr}$ alloys subjected to SPD and subsequent aging showed that a combination of high strengths of about $688 \mathrm{MPa}$ with a conductivity of $59 \%$ IACS, or $599 \mathrm{MPa}$ at $82 \%$ IACS can be achieved [913]. Thus, the combination of SPD and subsequent aging seems to be a promising direction for the simultaneous formation of high strength and electrical conductivity in the alloys of the $\mathrm{Cu}-\mathrm{Cr}-\mathrm{Zr}$ system. It worse to note, however, that as a result of SPD performed by equal channel angular pressing (ECAP) a microstructure with an average grain size of $250-300 \mathrm{~nm}$ is formed in $\mathrm{Cu}-\mathrm{Cr}$ $\mathrm{Zr}$ alloys. The degree of plastic deformation achieved by such a treatment reaches $\sim 9.2$.

It is known that SPD performed by HPT allows achieving of a much larger grain refinement as a result of strain degrees equal to $\sim 157$. In [14], $\mathrm{Cu}-\mathrm{Cr}-\mathrm{Zr}$ alloys subjected to SPD by HPT (the number of turns $\mathrm{N}=5$ ) with subsequent aging resulted in a tensile strength of about $750 \mathrm{MPa}$ with a conductivity of $59 \%$ IACS.

Thus, it can be seen that as a result of HPT with subsequent aging it is possible to substantially increase the strength properties while maintaining a sufficiently high level of electrical conductivity. In this paper, we investigated the effect of the strain degree which was 2 times greater than in [14] on the strength and electro conductivity of the $\mathrm{Cu}-0.5 \mathrm{Cr}-0.2 \mathrm{Zr}$ alloy.

\section{Experimental}

The copper alloy with chromium and zirconium $\mathrm{Cu}-0.5 \%$ $\mathrm{Cr}-0.2 \% \mathrm{Zr}$ (wt.\%) was chosen as the material for the studies. In order to obtain a supersaturated solid solution, the as-received rods with a diameter of $20 \mathrm{~mm}$ were

\footnotetext{
"Corresponding author: benjamin.wwei@163.com, sarkeeva.e@inbox.ru
} 
subjected to high-temperature heat treatment at $1000{ }^{\circ} \mathrm{C}$ for 0.5 hours, followed by quenching in a $5 \% \mathrm{NaCl}$ solution. As a result, the initial state (IS) was formed.

Furthermore, the rods were cut into discs $2 \mathrm{~mm}$ in thickness and subjected to HPT at room temperature. The disks were deformed under an applied pressure of $6 \mathrm{GPa}$. The number of revolutions $\mathrm{N}=10$, which corresponded to the true degree of $\sim 157$. HPT was carried out in a "hole" with a depth of $0.2 \mathrm{~mm}$. As a result of the HPT, samples of $\varnothing 20 \mathrm{~mm}$ and a thickness of $\mathrm{h}=2 \mathrm{~mm}$ were obtained.

Aging was carried out in air in an oven SUOL 45 at $450{ }^{\circ} \mathrm{C}$ for 1 hour.

To study the microstructure, an optical microscope (OM) OLIMPUS GX51 and a transmission electron microscope (TEM) JEOL 2100 were used.

The microhardness of the test samples was measured on a Duramin instrument under a load of $100 \mathrm{~g}$ and with a holding time of 10 seconds for the load.

Uniaxial tensile tests were carried out on an Instron 8801 small specimen testing machine at room temperature at a speed of $10^{-3} \mathrm{~s}^{-1}$. Samples with dimensions $10 \times 4 \times 4$ $\mathrm{mm}$ were cut perpendicular to the radial section of the disks. Three samples were tested for each condition.

Conductivity studies were carried out at a temperature $\mathrm{T}=23{ }^{\circ} \mathrm{C}$ by an eddy current method on flat samples. The accuracy is $\pm 2 \%$.

All investigations of microstructure and properties were carried out for regions located at a distance equal to half the radius of the disks.

\section{Results and discussion}

Fig. 1 shows the structure of the $\mathrm{Cu}-0.5 \% \mathrm{Cr}-0.2 \% \mathrm{Cr}$ alloy in the initial state. In general, the structure is characterized by a sufficiently high degree of homogeneity. The average grain size is $140 \pm 8 \mu \mathrm{m}$. At a given quenching temperature, the dissolution of the particles does not take place completely, a fine-dispersed phase is observed.

As already shown in previous studies, the composition of these precipitates corresponds to $\mathrm{CrCu}_{2}$ $[4,5]$. In addition, as shown in [6], the particles of $\mathrm{Cu}_{3} \mathrm{Zr}$ and $\mathrm{Cu}_{5} \mathrm{Zr}$ are also represented in the microstructure. The particles are arranged non-uniformly both in volume and in grain boundaries. The largest of them reach a size of 20 $\mu \mathrm{m}$.

Electron microscopic images of the state of the alloy after HPT and HPT and the subsequent aging are shown in Fig. 2, and 3. As a result of the HPT, a UFG structure was formed. The boundaries of the structure elements are mostly blurred. The electronogram for this state is ringshaped with well-defined individual reflexes evenly distributed around the ring (Fig. 2).

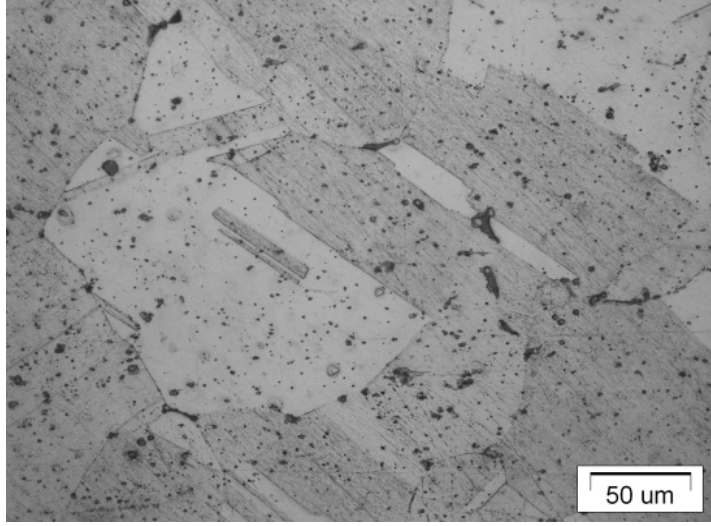

Fig. 1. The optical metallography of the IS state.

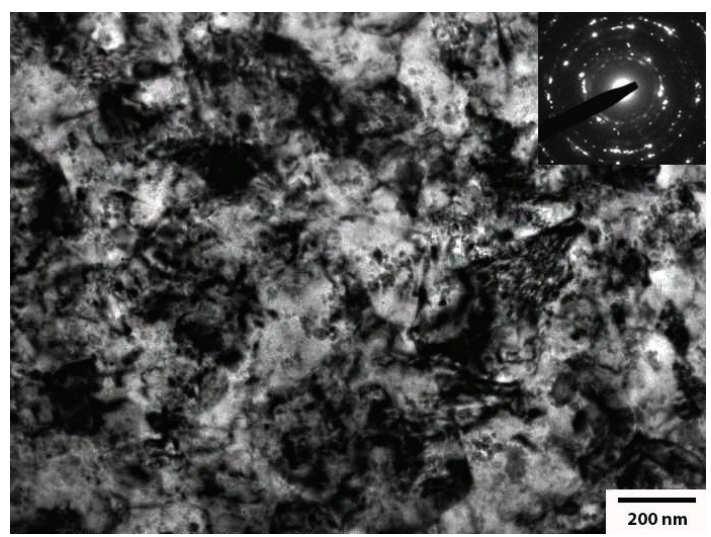

Fig. 2. TEM of the HPT state.

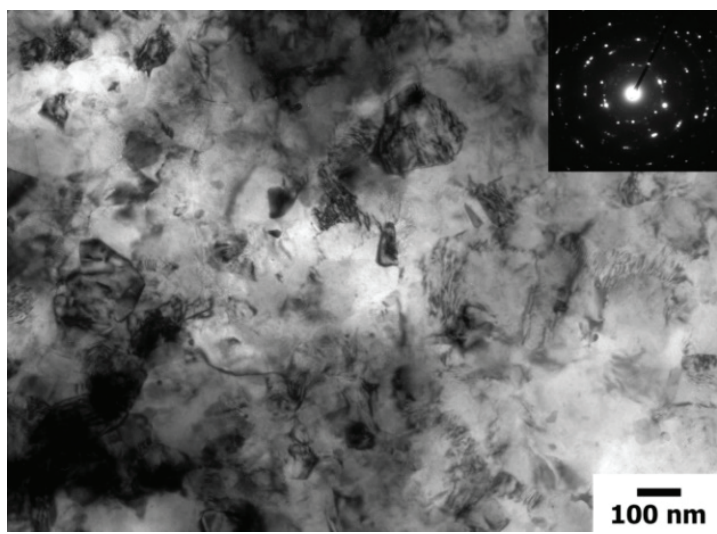

Fig. 3. TEM of the HPT + aging state.

Analysis of the dark field electron microscopic images for the HPT shows that the average size of the formed microstructure elements is $135 \pm 40 \mathrm{~nm}$ (Fig. 2). After HPT, no large particles are practically observed. Dispersed particles of about $5 \mathrm{~nm}$ in size are clearly visible.

As a result of aging, a microstructure, consisting of grains with clearly delineated boundaries, is formed (Fig. 3 ). The banded contrast along them indicates their perfection. The improvement of the microstructure is the result of relaxation processes, which are accompanied by the growth of grains. However, at the same time grains with blurred boundaries are preserved. The heterogeneity inside some of them indicates the preservation of the 
stressed state. The size of individual grains reaches 340 $\mathrm{nm}$, and the average grain size is $140 \pm 50 \mathrm{~nm}$.

In this case, part of the grains have a size of 20-40 nm. Particles of the second phase are visible in the microstructure. The shape of these particles is different. There are particles of round, oval, a regular hexahedron, a rhombus shapes, and also triangular particles. In the structure there are particles of different sizes. The size of round and oval particles is about $5 \mathrm{~nm}$, the size of particles with other shapes is $20 \mathrm{~nm}$. The average particle size is 10 nm. The particles are arranged non-uniformly both in volume and in grain boundaries.

Investigation of mechanical properties showed that the HPT leads to an increase in the microhardness values up to $2925 \pm 190 \mathrm{MPa}$ as compared to the microhardness of initial state equal to $845 \pm 20 \mathrm{MPa}$, i.e. 3.5 times (Table 1, Fig. 4).

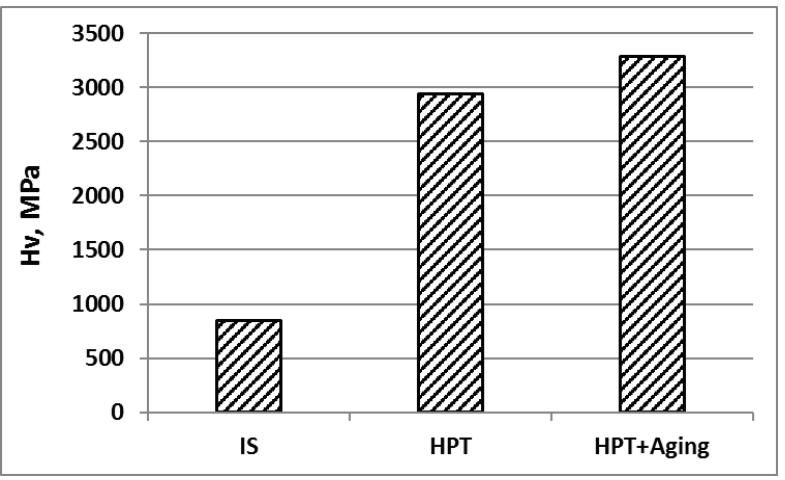

Fig. 4. The microhardness of $\mathrm{Cu}-\mathrm{Cr}-\mathrm{Zr}$ alloy after different treatments.

Fig. 5 shows the engineering strain-strain curves in coordinates $\sigma_{u}-\varepsilon$, obtained for samples in different states. In the initial state, the ultimate strength of the sample is $226 \pm 5 \mathrm{MPa}$. After HPT the strength of the $\mathrm{Cu}-\mathrm{Cr}-\mathrm{Zr}$ alloy is increased up to $820 \pm 5 \mathrm{MPa}$. Subsequent aging leads to an increase in strength up to $900 \pm 15 \mathrm{MPa}$.

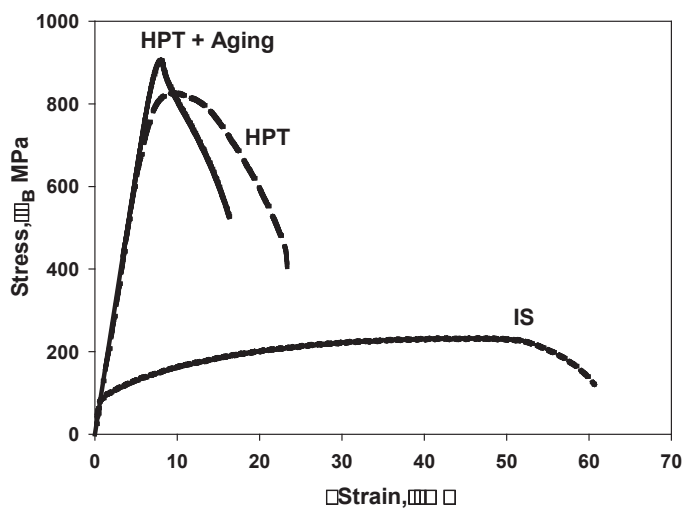

Fig. 5. The dependence of the flow stress upon strain $\varepsilon$, $\dot{\varepsilon}=10^{-3} \mathrm{~s}^{-1}, T=293 \mathrm{~K}$.

The results of mechanical tensile tests are well correlated with the results of microhardness measurements in Table 1.
Table 1. Mechanical characteristics of different states.

\begin{tabular}{|c|c|c|c|c|c|}
\hline State & $\mathrm{Hv}, \mathrm{MPa}$ & $\begin{array}{c}\sigma_{u}, \\
\mathrm{MPa}\end{array}$ & $\begin{array}{c}\sigma_{0.2}, \\
\mathrm{MPa}\end{array}$ & $\varepsilon, \%$ & $\begin{array}{c}\text { IACS, } \\
\%\end{array}$ \\
\hline IS & $845 \pm 25$ & $226 \pm 5$ & $84 \pm 1$ & $62 \pm 1$ & 31 \\
\hline $\mathrm{HPT}$ & $2925 \pm 150$ & $820 \pm 5$ & $730 \pm 20$ & $22 \pm 1$ & 33 \\
\hline $\begin{array}{c}\text { HPT+ } \\
\text { Aging }\end{array}$ & $3290 \pm 110$ & $900 \pm 15$ & $868 \pm 40$ & $16 \pm 1$ & 70 \\
\hline
\end{tabular}

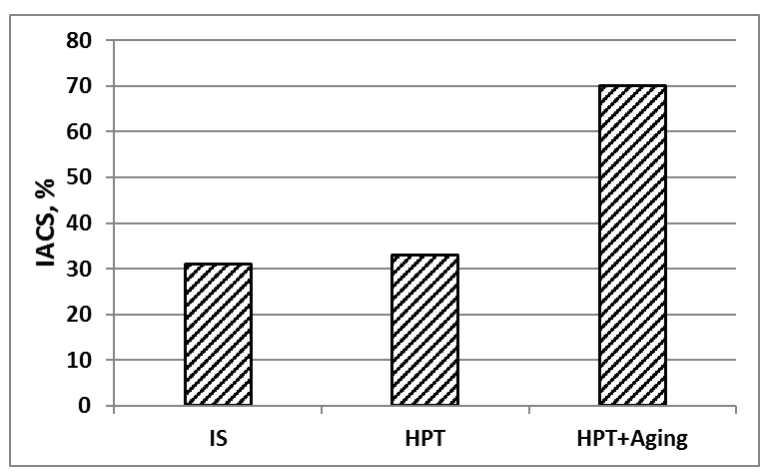

Fig. 6. The electrical conductivity after various treatments.

As can be seen, aging leads to an additional increase in microhardness from $2925 \pm 150$ to $3290 \pm 110 \mathrm{MPa}$, as well as to the restoration of electrical conductivity to $70 \%$ of IACS in Fig. 6. Hardening is due to the precipitation of dispersed particles during aging, which inhibits the growth of grains during aging and compensate for softening due to a certain growth of grains. The value of the electrical conductivity as a result of aging increases from $33 \%$ to $70 \%$ of IACS (Fig. 6).

\section{Conclusions}

Thus, as a result of the HPT, a high-strength UFG state with a grain size of $140 \mathrm{~nm}$ was formed in the $\mathrm{Cu}-\mathrm{Cr}-\mathrm{Zr}$ alloy. The aging leads to an additional increase in strength up to $900 \mathrm{MPa}$. In this case, the electrical conductivity is restored to $70 \%$ of the IACS. The increase both in strength and electrical conductivity indicates the occurrence of deformation-stimulated decomposition processes in a supersaturated solid solution.

The work is executed by the financial support of the Ministry of education and science within the framework of the project No. 16.1969.2017/PCh and the Science and Technology Bureau of Jiangsu Province, P.R. China under grant No. BY2016029-19.

\section{References}

1. H. Fuxiang, M. Jusheng, N. Honglong, G. Zhiting, L. Chao, G. Shumei, Y. Xuetao, W. Tao, L. Hong, L. Huafen, Scr. Mater. 48 (2003)

2. W.X. Qi, J.P. Tu, F. Liu, Y.Z. Yang, N.Y. Wang, H.M. Lu, X.B. Zhang, S.Y. Guo, M. S. Liu, Mater. Sci. Eng. A. 343 (2003)

3. N. Bochvar, Cr-Cu-Zr (Chromium-CopperZirconium). In G. Effenberg, S. Ilyenko, editors. Non-Ferrous Metal Systems. Part 2. Landolt- 
Börnstein - Group IV Physical Chemistry, Springer Berlin Heidelberg; V 11C2 (2007)

4. W.X. Qi, J.P. Tu, F. Liu, Y.Z. Yang, N.Y. Wang, H.M. Lu, X.B. Zhang, S.Y. Guo, M. S. Liu, Mater. Sci. Eng. A. 343 (2003)

5. J.P. Tu, W.X. Qi, Y.Z. Yang, F.Liu, J.T. Zhang, G.Y. Gan, N.Y. Wang, X.B. Zhang, M.S. Liu, Wear 249 (2002)

6. N.Y. Tang, D.M.R. Taplin, G.L. Dunlop, Mater. Sci. Tech. 1 (1985)

7. R.Z. Valiev, R.K. Islamgaliev, I.V. Alexandrov, Progress in Mater Sci. 45 (2000)

8. R.Z. Valiev, I.V. Alexandrov, Bulk nanostructured metal materials: preparation, structure and properties (Akademkniga, Moscow, 2000)

9. R.K. Islamgaliev, K.M. Nesterov, Y. Champion, R.Z. Valiev, Mater. Sci. Eng. A. 63 (2014)

10. W. Wei, K.X. Wei, F. Wang, Q.B. Du, I.V. Alexandrov, J. Hu, Mater. Sci. Eng. A. 528 (2011)

11. G. Purcek, H. Yanar, O. Saray, I. Karaman , H.J. Wear 311 (2014)

12. Vinogradov A., Ishida N., Kitagawa K., Kopylov V., Acta Mater. 53 (2005)

13. Vinogradov A., Patlan V, Suzuki Y., Kitagawa K., Kopylov V., Acta Mater. 50 (2002)

14. D.V. Shangina, N.R. Bochvar, M.V. Gorshenkov, H. Yanar, G. Purcek, S.V., Mater. Sci. Eng. A. 650 (2016) 